\title{
SCIENTIFIC TALES AND DEMOCRATIC PROCESSES IN AN AGE OF GLOBAL WARMING: THE AFRO NIGERIAN CHAPTER
}

\section{Evaristus E. Ekweke}

\section{Introduction}

It has been a concrete issue for debate that philosophy and science are after all not divorced from one another. This so-called debate has, over the centuries and over the years, been the concern of different classes of people. The presence of class and interest groups has often made this debate overly political, if overtly sectionalist. Philosophers on the one hand have always used every logic to present people like Aristotle, Democritus, Hypocrates and others as being philosophers and scientists in one single swoop. The reason is that philosophy, as the science of an ordered system of thinking, is taken to be, in most part, the first science. And if natural science is anything to go by, it is because it thrives in a given methodic forum.

The debate may remain. Yet nature is larger than all debates. For both science and philosophy are scions of nature writ large. Whether philosophy is the first science or whether empirical science (experimental science) is on its own divorced from the abstract cacophonies of philosophy leaves much to be desired if we do the debate just for its sake. In modern times, however, empirical science operates in seemingly different wave-lengths as philosophy. But where they meet is at the level where some tensions rock the boat of scientists. Then they may need the analysis of philosophy in order to forge ahead.

If we take a recourse to the history of what could be called science from antiquity we discover that between Eudoxus $\left(4^{\text {th }}\right.$ century b.c), ${ }^{1}$ a Greek mathematician from the school of Plato, and Ptolemy (c.A.D. 130), considerable science and philosophy had been done at different levels progressively. At the time in Question, there had been arguments and counter arguments in the particular area of planetary science, astronomy and cosmology, the disciplines of which are delicately interwoven. Particular tension reigned on two observational and observable points. These were the behaviour, nature and process of what I have decided to call constituents in 
planetary nature. Some scientists and philosophers of the early times took sides; some discussed the planets as being physically charged and some others took to the geometrically numerical or mathematical analysis of the behavior of the cosmological planetary, constituents of our space.

John L. Russell reports that Aristotle relied on the Babylonian astronomers in fabricating his own explanatory norm with reference to the planetary "science' in his (Aristotle's) cosmology. The Babylonian astronomers, "...had observed no change in the celestial bodies over a period of many centuries." 2 So Aristotle "... postulated that these bodies are composed of a special sort of matter which is, of its nature, intrinsically immutable and eternal. He argued from this, that their natural motion must be uniform circular since this is the only type, which, in a closed system, can continue unchangeably for all eternity. He further postulated that the planets are embedded in a complex system of rigid concentric spheres, each of which rotates with its own proper uniform motion and at the same time is carried round by the sphere immediately outside itself." 3 Even though Aristotle was doing his explanation of the nature of the planets from point of view of the physical stance of the universe, his was sufficiently mechanical, if scientific. His position was not so much of a theory that demands some mathematical accuracy. Rather it sought to give meaning to the constituents of nature as is found among the planets.

As has been hinted above, there were some Greek mathematical astronomers among who were Eudoxus, Callipus, Heraclitus, Hipparchus, and Apollonius. ${ }^{4}$ These wise men, philosophers and scientists alike, were particular about accuracy through different but uniform circular motions, linear velocity which was a later development - the theory of electric and epycyclic paths plus some complicated equant points added by Ptolemy. ${ }^{5}$ The scientific attitude of the Greek, so astronomical and cosmological in nature, influenced their medieval successors who largely inherited it, even though with some moderation.

It is however, interesting to note that the ancient Greek thinkers we mentioned above had styles of the explanation of the planets that were different. It is all the more interesting to note that they had one motive. This one motive finds expression in a common 
interest, which was a selfless study of the universe in order to perform and improve the knowledge of man about his environment. They were geometrical, mathematical and physical. They were research conscious, without being violently capitalistic. That is why this paper wants to suggest that a better scientific study of the universe will help as to know the world better. A given capitalist politics that slaughters the knowledge of our environment for the benefit of man on the altar of economic but deadly glories terribly and horribly begs the question.

\section{Tales of Science and Political/Democratic Processes}

It is on record ${ }^{6}$ that politics has, in history, affected scientific research, and the kind of politics, referred to here is eclectic relative to what is being politicized about. Even though research, through observation, experiment and the like, has been playing great roles in especially modern science yet politics has been involved. A given intellectual politics necessitated an interpretation of the universe and analyses of the history and content of matter following a given paradigm that lasted too long. Aristotle's science, as I call it, exerted a lot of influence on even $16^{\text {th }}$ century enlightenment science, thought and philosophy. That is why "At the beginning of the seventeenth century the accounts of matter and properties taught in the universities throughout Europe remained versions of Aristotle and his scholastic commentators. Central to these were a belief in the four elements of earth, water, air and fire, and the rejection both of the possibility of a vacuum (nature abhors a vacuum) and of any kind of atomic theory. The properties or qualities of bodies, of which there were supposed to be four primary ones, heat, cold, dryness and wet, were linked with the four elements, thus water was a combination of prime matter plus the qualities of cold and wet. ${ }^{7}$ This influence of Aristotle, which lasted into the $17^{\text {th }}$ century, was a kind of intellectual politics that affected the doing of science. But what is remarkable is that even given the disturbances of politics science continued to be and to impress the people that populate the world. It was also the $17^{\text {th }}$ century that gave birth to a fresh appreciation of science. Thus the traditional interpretation of matter gave way to a revolutionary restructuring ${ }^{8}$ of empirically scientific theories. This mentality brought new vision 
and allowed fresh wind to blow into a somewhat renewed sense of science. "Copernicus' vision of a moving earth and a heliocentric universe found strong support in the observations of Galileo with the telescope in 1609, but the full intelligibility of the heliocentric view awaited a comprehensive physics to replace that of Aristotle. This new physics gradually took shape during the seventeenth century with Galileo and Rene Descartes prominent in its formulation. The zenith of this development was the publication in 1687 of Newton's Mathematical Principle of Natural Philosophy, the Principia, which provided a comprehensive mechanics that gave physical sense to the idea of a moving earth and provided a deep understanding of central physical concepts. It also generated an accuracy in scientific calculation and prediction scarcely previously conceived."9 Copernicus-the revolutionist -, Galileo - the innovator, and Descartes - the mathematical initiator - are the names that make initial waves in the tension of scientific paradigms that witnessed a transition from the Aristotelian natural philosophy or science of the universe to the climatic Newtonian classical mechanics of absolute space, of absolute time and of gravitational processes implicating a given theory of motion governed by laws (of nature); processes, rich in tests and observations that culminate in experiments of sorts. There is something special, therefore, about the new science. For the proponents ${ }^{10}$ by this proffers a system that being axiomatic and method laden is capable of being both predictive and accurate. ${ }^{11}$ This is a force that was earlier scarcely in existence in the sense of scientific thinking. Nature had hardly earlier been investigated, as did the new kind of science. An observational process was not the only question. There was a further question of an investigative brand of explanation that was attached to a fresh approach towards a rediscovery of the constituents of nature.

The birth of the new science since the $17^{\text {th }}$ century has been a spring board for contemporary and post modern progress in, say natural science. For arguments abound in favour of a continuous developmental method for which science is known since history. For Einstein, for instance, "We can distinguish various kinds of theories in physics. Most of them are constructive. They attempt to build us a picture of the more complex phenomena out of the material of a relatively simple formal scheme from which they stand out. Thus the 
kinetic theory of gases seeks to reduce mechanical, thermal, and diffusional processes to movement of molecules - i.e. to build them up out of the hypothesis of molecular motion. When we say that we have succeeded in understanding a group of natural processes, we invariably mean that a constructive theory has been found which covers the processes in question. ${ }^{12}$ The doing of science is a scheme. It is an exercise that thrives in a principle of purpose having the universe as its object and discovery of the quiddity of phenomena as its goal.

It is of some importance to recall, however, that tales of science explore the history of Einstein's undaunted effort and commitment to make the new physics, for instance, purely a revolution. With reference to his findings in the Quantum Hypothesis, ${ }^{13}$ Einstein's discoveries in electromagnetic fields were a great achievement. This is one of his scientific activities that lend credence to his theories of relativity that proved more plausible than the theories advanced by Isaac Newton. In all these arguments concerning the history of science and principal actors on the stage of natural science, there is a single characteristic running through the whole tale of natural science it is a story of success. Success here does not suggest a final conquest of the universe. It is a kind of success that suggests steadfastness in undaunted research. It is a success because wise men who have played significant roles in the enterprise of science have been consistent in their endeavour to give fresh meaning to phenomena. There are criticisms about styles of approach. There are debates about the acceptances of hypotheses and conjectures $^{14}$ as orthodox empirically scientific theories. There are also systems devised by some so-called members of the community of scientists used in decisions that brand theories fit or not to effect the emergence of paradigms ${ }^{15}$ in a given scientific status quo or dispensation. And all these are activities in the enterprise of science that find expression in strict academic as well as intellectual expertise.

Since this is the case, efforts should be made by government and society to empower science for the benefit of man. Records, however, have it that governments with the collaboration of some dissident scientists have made efforts to influence scientific activities to their favour. ${ }^{16}$ In this direction researches have been manipulated 
and findings have been marginalized, jeopardized and misdirected. As much as this attitude could find some argument to ratify itself, it is detrimental to science. Free scientific research is advocated for the good of man and his universe. This would enhance a genuine study of the universe in order to surprise nature before it surprised man.

\section{The Politics of Global Warming and the Implications of Tales of Science.}

This issue of global warming demands a scientific research that is rather late. It is late in the sense that we allowed the effects to precede our study of it that would have availed man knowledge of a given catastrophe. With reference to this A.N. Whitehead has made bold to say "we are entering an age of reconstruction, in science, and in political thought. Such ages, if they are to avoid ignorant oscillations between extremes, must seek truth in its ultimate depths. There can be no vision of this depth of truth apart from a philosophy which takes full account of "ultimate abstractions... to explore.",17 This Whiteheadian recipe is actually timely in our generation. We need, in the language of post-modernity, to reconstruct our constructs in both science and philosophy. Our concepts and thinking in the sense of science is aching for some constructive change in our progressive and empirical thought prowess. A given reconstruction is meant here where structures of research in science have got to entertain a fresh approach in respect of observation, prediction and production. This would implicate a politics of consideration for the doing of real science that should have time to do research and study the researched materials. A philosophy that takes care of ultimate abstractions in the sense of a deep quest for knowledge and a science of phenomena that thrives in concrete explanations is needed to seek for truth in its ultimate depth like Whitehead $^{18}$ tells us. The attitude that is suggested wants to implicate a philosophy of action that analysis a committed kind of science whose enterprise is to make concerted efforts towards a study of the constituents of nature in respect of man, the paragon of the universe. A democratic politics of natural science should be interested in giving the above mentioned exercise a certain measure of some freedom of operation. 
If we had taken cognizance of this style of science and philosophy which earlier activities of 'homo sapiens' would do, we would not experience the so-called "Global Warning"" that we have today. It is estimated that majority of the cause of global warming is the collective attitude of modern $\operatorname{man}^{20}$ whose greed has pushed him into the shackles of capitalism and quagmire of materialism, making money at the expense of the life of mother earth and those who inhabit. The same earth. We are told that the so-called "greenhouse gas" 21 emitted from industries and like loci do much of the harm that are orchestrated by the effect of the global warming in question.

It will, at this juncture, be necessary to ask: what is Global Warming? It is taken to be "the increase in the average temperature of the earth's near-surface air and ocean since the mid-twentieth century and its projected continuation." 22 Heat has been identified as the cause of global warming. But this heat is not abnormal, because sometimes, it constitutes only an average temperature for the Earth. But it is when the content of the heat becomes overly thermal, causing increase in the capacity of the temperature embedded in the heat that global warming occurs. On a more elaborate note, John Weier and H. Richeel reports that "Global warmth begins with sunlight. When light from the sun reaches the Earth, roughly 30 percent of it is reflected back into space by loads, atmospheric particles reflective ground surfaces, and ever ocean surf. The remaining 70 percent of the light is absorbed by the land, air and ocean heating our planet's surface and atmosphere and making life on Earth possible. Solar Energy does not stay bound up in Earth's environment forever." 23 Global warming is also to a large extent aided by the action of sunlight warmth upon the Earth. When it heats all facets of the components of the Earth, some considerable warmth occurs. It is, however, evident that the heat from the sun could not cause so much damage since the action of this makes life on earth possible. Thus the truth of the matter is that man's industrial activities that emit thermal-charged gas, popularly called green house gas that joins the air traveling heaven wards, cause a greater warmth. For it comes, in contact with the already heated circumstance of the Earth's atmosphere.

We have so far made an attempt at presenting what is referred to as global warming. There may be arguments against 
scientific prediction, weather forecasts ${ }^{24}$ and its pre-empting of real occurrences in the sense of the effects of global warming. Be that as it may, results from Climate models are always probabilistic akin to the inductive process of observation through confirmative probability and evidence. Incidentally, probability has some foundation from which a thing could be probable or not. So in the case of the predications about the effects of global warming or the nature of the weather according to the behavior of planetary warmth, there are conditions that are constant over a period of time as a given large area. In this case, predictions are universalized. This universalization had held water over time and in space with little or no variabilities. In this case, prediction and forecast become more or less plausible. Thus global warming and its concomitant effect is real given the above empirically and naturally scientific argument. This is the reason why government blue prints and decision making in modern times ought to support research in favour of such phenomena in our natural environment that can embarrass us.

\section{Africa/Nigeria in the Face of Global Warming in a World of Science and Technology.}

Even though this is debatable, Global Warming is a scion of some tales of science associated with the mutational nature of the cosmos. If we go by the politics of the Big Bang, ${ }^{25}$ the whole universe was born out of a combustible happenstance that was overly gaseous (of gas). By this decimal, the universe is born of a system or structure that is of some heat. So that the movement of the Earth as has been mentioned above, is bound to be thermal: of heat processes. It, therefore, means to study this earth and like realities, we have to stake, time, space, energy and money to do worthwhile research. This is a task that is not to be left to Afro-Nigerian scientists alone. Politicians, sociologists, philosophers and indeed other experts carefully chosen are to be involved in this.

One of the reasons why we are insistent in crying out so loud, is because "Global Warming is also putting pressure on ecosystem, the plants and animals that co-exist in a particular climate. Warmer temperatures have already shifted the growing season in many parts of the world" 26 This is both a scientific factual 
observation and a climatic truism. In our current weather dispensations the effects of Global Warming can hardly be over emphasized. Given that Africa nay Nigeria is already a hot environment, our chances of escaping the visits of the global warming effect is very meager. So we should have to galvanize redoubled efforts to carry out research towards tackling these effects so that they be less devastating. It has also been observed that "the people who will be hardest hit will be residents of poorer countries who do not have the resources to fend off changes in climate. As tropical temperature zones expand, the reach of some infectious diseases like malaria will change. More intense rains and hurricane, rising sea levels and fast-melting mountains glaciers will lead to more severe flooding. ${ }^{27}$ The condition outlined above that favour the effects of global warming are grossly evident in Africa, especially Nigeria. The issue of "rains" rising sea level" and "flooding" are our lots in Nigeria since we live on the west coast of Africa along which these consequences are "grosso modo" possible. As much as we do not want to be scientific, prophets of doom, we want to, at the same time sound as imminent as the case at hand is. It is no longer an announcement of the existence of some climatic or weather catastrophe or natural disaster caused by global warming somewhere else. It is the presentation of a scientific fact that is at hand which can rock the boat of some economic progress in our continent and in our country. The case of Africa is equal to any other case that has experienced the kind of hazards produced by global warming as in the case of "Katherina" and the like. It is not a story told in a reported speech, it is a possible experience to be lived that would make or mar a people, the objects of this experience.

It is true that the afro-Nigerian democratic processes are yet finding their feet in the global polity. Yet they can chart a good political path in favour of the phenomenon of global warming. For "the struggle to direct the pursuit and applications of scientific knowledge-power in Africa is not yet over; indeed it has yet to begin." 28 Our political policies in Africa and in Nigeria are not the worst eclectically. The application of directives, in the Nigerian politic may be in consonance with our Nigerian vision. Yet and like H. Lauer suggests, Nigeria has to be cognizant of its role in maintaining the positive and negative behaviours of the world 
around her. In the present scientific dispensation, precedence is given to study, research and expertise. Thus political policies will be worth it, in this wise, when they recognize the importance of scientific research and make bold to sponsor it. That is the more reason why it is pertinent to listen to experts on techo-science and global warming while the government makes decisions about the environment - that is the world around us - and human beings ${ }^{29}$ who inhabit it.

\section{Conclusion}

The claims we have made in this paper do not bind forever. The present paradigm of empirical science does not subscribe to a given scientific theory that is dogmatic about its claims. That is why Christopher Ray maintains that "all our theoretical choices have a conventional character the empirical evidence can never tie us down to just one view; that is our choice of theory must always, be under determined by the empirical data." ${ }^{30}$ What is implied here is that we have made recourse to empirical natural science; we have presented some claims and made suggestions. But we do not intend to insist on a particular approach to a given empirical datum as we want to know more about the world around us, as in the case of the phenomenon of global warming. The case of the global warming has been declared a case of emergency. We have suggested that an approach to a better knowledge of it through empirical natural science with its probability and evidence is largely efficacious. Our argument wants also to be relative and somewhat conventional by maintaining that another scientific method could also do the job. However, to arrest the adverse effects of such phenomena as global warming a naturally scientific approach through the fundings of the government treasury is required. This is our humble submission.

As we started this paper we made recourse to a tale of science that involves philosophy where a debate was put in place as to the relationship between the two, disciplines. They reason for this that the tool used in producing this paper is not only naturally scientific. It is not only philosophical. The analyses involved are drawn from a philosophy of the natural science with particular reference to physics and cosmology. We have gone further to identify the efforts made by ancient thinkers to do a "science" of 
their universe. Two approaches were distinguishable. The one was a physical approach to the characterization of matter while the other one was a numerical or geometrically mathematical approach to a study of phenomena. But we discovered that their common motive was a general consciousness of their environment.

We have traced the history of science and discovered democratic and political influence on the attitude of the progress of science with particular reference to cosmology and astro-physics. Even though these upheld science and scientists maintained their commitment especially with reference to the growth of science. It is however through a progressive kind of science that we can do a science of the universe and also of our environment.

Efforts have been made to address the issue of global warming defining, describing, and scientifically situating it in the world. Blames have been apportioned to man who allowed things, like green house gas to instigate global warming. We have attempted to suggest a scientific solution towards avoiding adverse effects of global warming. The world, Africa and Nigeria have to be involved in an expertise kind of approach in studying our environment and taking an appointment with a cordial encounter with the world around us.

Our scientific know-how and our philosophic reasoning are enough to remind us that we are confronted with real issues. The populace, the government and the academia have to come together to attend one common school. Here everybody will resolve to fight global warming with the right tools. 


\section{References:}

1. See RUSSEL, J., "Kepler and scientific Method" in Bulletin No 68, Secretariat for Scientific Question, Pax Roma, 2007, p.24.

2. Ibid, p. 24

3.Ibid, p. 24

4. Ibid, p. 24

5. Ibid, p. 24

6. See LAUER, H. (ed.), History and Philosophy of Science, Hope

Publications, Ibadan, 2003, pp.10-16.

7. ROGERS, G.A.,"Science and British Philosophy: Boyle and Newton, "in BROWN, G. (ed.), British Philosophy and the Age of Enlightenment, Routledge, New York, 1996, p.46.

8. KUHN, T.S., The Structure of Scientific Revolutions, University of Chicago Press, London. 1970, pp. 111-125.

9. ROGERS, G.A., "Science and British Philosophy: Boyle and Newton “... Op. Cit., p.43.

10. H.LAUER reports that "Bacon urged that the institution of the New Science should be broadly political and civic organs of partnership between entrepreneurs, scholars and the ruling elite in the interest of promoting social welfare. The methods of the New Science should be judged by their observable results in the advancement of social welfare". This kind of science that implicates politics will be advocated in an environment whose global warming is being fought. See LAUER, H, (ed.), History and Philosophy of Science, op. cit., p.12; see also ROGER, G.D. Science and British Philosophy: Boyle and Newton, op. cit., p.43.

11. See ROGERS, G.A., "Science and British Philosophy... op.cit., pp.62-64.

12. See EINSTEIN, A., Ideas and opinion, in COLODNY, R.G., (ed) From Quarks to Quasars: Philosophical Problems of Modern Physics, University of Pittsburg Press, Pittsburg, 1986, p.357.

13. See STACHEL, J., "Einstein and the Quantum: fifty years of struggle" in COLODNY, R.G. (ed.) Philosophical Problems of Modern Physics, op. cit., p. 357.

14. See POPPER, K.R., Conjectures, and Refutations, the Growth of Scientific knowledge, Routledge, London, 1989, pp.33-65.

15. See KUHN, T.S. The Structure of Scientific Revolutions, op. cit., pp.42,ff.

16. See LAUER, H. (ed.), History and Philosophy of Science, op. cit., p.14.

17. WHITEHEAD, A.N., quoted in COLODNY, RG. (ed.) op.cit., p.xii.

18. Ibid., p. xii.

19. Global Warming will not affect all places on Earth the same way.

Climate models, predict that warming will be greatest in the Arctic and 
over land. Models also give a range of temperature predictions based on different emission scenarios. If human limit green house gas emission (low Growth), then the temperature change over the next century will be smaller than the change predicted if humans do not limit emission, (high Growth). (See http earthobservation, nasse. Gov/library/global warming/printall.php) 20. Far from being some future fear, global warming is happening now, and scientists have evidence that humans are to blame. For decades cars and factories have spewed billions of tons of green house gases into the atmosphere, and these gases caused temperatures to rise between $0.6^{\circ} \mathrm{C}$ and $0.9^{0} \mathrm{C}\left(\mathrm{L} .08^{0} \mathrm{~F}\right.$ to $\left.1.62^{0} \mathrm{~F}\right)$ over the past century. The rate of warming in the last 50yrs was double the rate observed over the last 100 years... (see http.earthobservatory...)

21 . The green-house effect was discovered by Joseph Fourier in 1824 and was first investigated quantitatively by Svante Arrhenius in 1896. It is the process by which absorption and emission of infrared radiation by atmospheric gases warm a planet's lower atmosphere and surface. (see Wikipedia).

22. Wikipedia, op.cit.

23. Ibid

24. See http//earthobservatory.nasa.gov.

25. LEMAITRE, G., The Big Bang and George Lemaitre,Barton, 1984, pp.280ff.

26. See http//earthobservatory, op.cit

27. Ibid

28. LAUER, H. (ed.), History and Philosophy of science op.cit., p.16

29. See BARROW, J.D and TIPLER, F.J., The Anthropic Cosmological

Principle, Oxford University Press, Oxford, 1988, pp.159ff.

30. RAY, C., Time, Space and Philosophy, Routledge, London, 1991, p.49 